\title{
Ripple Effect in the Supply Chain: An Analysis and Recent Literature
}

\author{
ALEXANDRE DOLGUI ${ }^{1}$, DMITRY IVANOV ${ }^{2}$, BORIS SOKOLOV ${ }^{3}$ \\ ${ }^{1}$ IMT Atlantique, LS2N, CNRS \\ La Chantrerie, 4, rue Alfred Kastler, 44300 Nantes, France \\ email: alexandre.dolgui@imt-atlantique.fr \\ ${ }^{2}$ Berlin School of Economics and Law, Department of Business and Economics \\ 10825 Berlin, Germany; Phone: +493085789155; email: divanov@hwr-berlin.de \\ ${ }^{3}$ ITMO University Saint Petersburg, Russia \\ ${ }^{4}$ Saint Petersburg Institute for Informatics and Automation of the RAS (SPIIRAS) \\ V.O. 14 line, 39199178 St. Petersburg, Russia \\ E-Mail:sokol@iias.spb.su
}

\author{
*Corresponding author \\ Prof. Dr Dmitry Ivanov \\ Berlin School of Economics and Law \\ Department of Business and Economics \\ Professor of Supply Chain Management \\ 10825 Berlin, Germany \\ Phone: +493085789155 ; \\ email:divanov@hwr-berlin.de
}

\begin{abstract}
In this study, the ripple effect in the supply chain is analysed. Ripple effect describes the impact of a disruption propagation on supply chain performance and disruption-based scope of changes in supply chain structural design and planning parameters. We delineate major features of the ripple effect as compared to the bullwhip effect. Subsequently, we review recent quantitative literature that tackled the ripple effect explicitly or implicitly and give our vision of the state of the art and perspectives. The literature is classified into mathematical optimization, simulation, control theoretic, and complexity and reliability research. We observe the reasons and mitigation strategies for the ripple effect in the supply chain and present the ripple effect control framework that includes redundancy, flexibility, and resilience analysis. Even though a variety of valuable insights has been developed in the said area in recent years, some crucial research avenues have been identified for the near future.
\end{abstract}

Keywords: Supply Chain Dynamics; Supply Chain Risk Management; Supply Chain Resilience; Supply Chain Design; Supply Chain Engineering 


\section{Introduction}

On October 17, 2016 as a result of an incorrect maintenance operation on a pipeline at BASF facility in Ludwigshafen (Germany), there was an explosion and subsequent fires at North Harbor, a terminal for the supply of raw materials such as naphtha, methanol and compressed liquefied gases. More than 2.6 million tons of goods are handled there each year and an average of seven ships a day moor at its docks. Two steam crackers, the starting point for producing basic chemicals, needed to be stopped because they could no longer be supplied, and 22 were only partially working. The two steam crackers could have been restarted two days later, but only in May 2017 was the concept for reconstruction released whereby the reconstruction should be completed by September 2017. Restricted production output, a daily revenue decrease of $10-15 \%$ as compared to the previous year during the disruption period, impact on the basic chemicals division (about $21 \%$ of sales), delivery delays, limited access to key raw materials, exhausted product inventories, and a forecasted impact on $6 \%$ of BASF's annual earnings were some of the consequences of this incident (FAZ 2016, Chazan 2016, Matthews and Sachgau 2016, SWR 2017). Logistics was temporarily shifted from ships and pipelines to trucks and trains. BASF was in close contact with its customers to keep them informed about the current availability of products to minimize the impact on customer deliveries. Because of BASF integrated "Verbundsystem" (networking system), comprised of various plants and delivery systems for feedstocks, the incident had an impact along the global supply chain (SC). This high and long-term impact is the so-called ripple effect (Ivanov et al. 2014a,b).

Throughout publications on SC disruption management, the details of empirical or modeling methodologies differ. Yet on a basic level, the majority include disruption, disruption impact on operational and strategic economic performance and stabilization and recovery policies: most SC disruption studies analyse how one or several changes ripple throughout the SC and affect performance. Correspondingly, the literature proposes the ripple effect in the SC (Ivanov et al. 2014a).

Disruption impacts SC performance and then propagates, affecting SC structural design and planning parameters: this reality is described by the ripple/domino effect. In short, disruption lays bare SC structural dynamics (Ivanov and Sokolov 2010, Ivanov et al. 2010, 2013, 2014a,b, 2015, 2017a,b, Choi et al. 2016, Scheibe and Blackhurts 2017, Ouang and Hara 2017, Ivanov 2018). Disruptions which affect the integrity of the SC dynamic might include fires at distribution centres, floods and tsunamis at production facilities, supplier legal conflicts, or strikes at airlines or railway companies (Tang 2006, Chopra and Sodhi 2014, Simchi-Levi et al. 2015, Ho et al. 2015, Behzadi et al. 2017, Mizgier 2017). Table 1 summarizes recent disruptions and their impacts on performance in the SC.

Table 1 Examples of disturbances and disruptions in SCs (extended from Ivanov and Sokolov 2010)

\begin{tabular}{|l|l|l|}
\hline Factor & Example & Impacts \\
\hline Terrorism & September 11 & Five Ford plants were closed for a long time \\
\hline
\end{tabular}




\begin{tabular}{|c|c|c|}
\hline Piracy & Somali, 2008 & Breaks in many SCs \\
\hline \multirow[t]{4}{*}{ Natural disasters } & $\begin{array}{l}\text { Earthquake in Thai- } \\
\text { land, } 1999 \\
\text { Flood in Saxony, } \\
2002 \\
\text { Earthquake in Ja- } \\
\text { pan, } 2007\end{array}$ & $\begin{array}{l}\text { Apple computers' production in Asia was paralysed } \\
\text { Significant production decrease at VW, Dresden } \\
\text { Production breakdown in Toyota's SCs amounted to } \\
55,000 \text { cars }\end{array}$ \\
\hline & $\begin{array}{l}\text { Hurricane Katrina, } \\
2006\end{array}$ & $\begin{array}{l}\text { This storm halted } 10 \%-15 \% \text { of total US gasoline pro- } \\
\text { duction, raising both domestic and overseas oil prices }\end{array}$ \\
\hline & $\begin{array}{l}\text { Earthquake and } \\
\text { tsunami in Japan, } \\
2011\end{array}$ & $\begin{array}{l}\text { Massive collapses in global automotive and electronics } \\
\text { SCs; Toyota lost its market leadership position }\end{array}$ \\
\hline & $\begin{array}{l}\text { Floods in Chennai, } \\
\text { India in } 2015\end{array}$ & $\begin{array}{l}\text { Production of academic literature was stopped at many } \\
\text { international publishing houses }\end{array}$ \\
\hline \multirow[t]{3}{*}{$\begin{array}{l}\text { Man-made } \\
\text { disasters }\end{array}$} & $\begin{array}{l}\text { Explosion at BASF } \\
\text { plant in Ludwigs- } \\
\text { hafen in } 2016\end{array}$ & $\begin{array}{l}15 \% \text { of raw materials were missing for the entire } \mathrm{SC} \\
\text { Production of some products at BASF were stopped for } \\
\text { many weeks }\end{array}$ \\
\hline & $\begin{array}{l}\text { Fire at distribution } \\
\text { center of e- } \\
\text { commerce retail } \\
\text { company ASOS in } \\
2005\end{array}$ & Delivery stopped for a month \\
\hline & $\begin{array}{l}\text { A fire in the Phil- } \\
\text { lips Semiconductor } \\
\text { plant in Albuquer- } \\
\text { que, New Mexico } \\
\text { in } 2000\end{array}$ & $\begin{array}{l}\text { Phillips's major customer, Ericsson, lost } \$ 400 \text { million } \\
\text { in potential revenue }\end{array}$ \\
\hline Political crises & “Gas" crisis 2009 & $\begin{array}{l}\text { Breaks in gas supply from Russia to Europe, billions of } \\
\text { losses to GAZPROM and customers }\end{array}$ \\
\hline Financial crises & Autumn 2008 & $\begin{array}{l}\text { Production decrease or closing; breaks in SCs through- } \\
\text { out }\end{array}$ \\
\hline Strikes & $\begin{array}{l}\text { Strikes at Hyundai } \\
\text { plants in } 2016\end{array}$ & Production of 130,000 cars was affected \\
\hline $\begin{array}{ll}\text { Legal contract } \\
\text { disputes }\end{array}$ & $\begin{array}{l}\text { Volkswagen and } \\
\text { Prevent Group con- } \\
\text { tract dispute in } \\
\text { summer } 2016\end{array}$ & $\begin{array}{l}\text { Six German factories face production halt on parts } \\
\text { shortage; } 27,700 \text { workers are affected, with some sent } \\
\text { home and others moved to short-time work }\end{array}$ \\
\hline
\end{tabular}

The ripple effect occurs when a disruption, rather than remaining localized or being contained to one part of the SC, cascades downstream and impacts the performance of the SC. This impact might include lower revenues, delivery delays, loss of market share and reputation, and stock return decreases - the cost of all of which could be devastating (Hendricks and Singhal 2005). Therefore, in order to develop network-based supply concepts, low-frequency-high impact disruptions must be 
evaluated and understood through methodical elaborations. Ripple effect analysis considers that disruption and recovery actions change SC structural dynamics, impact operations execution and affect sales, service level and costs.

The ripple effect, which deals with low-frequency-high-impact disruption or exceptional risk, represents an inverse of the bullwhip effect, which considers for low-frequency-high-impact risks, which are operational and recurrent (Liberatore et al. 2012; Ivanov et al 2014a, 2014b, 2015, 2016a, 2016b; Sokolov et al. 2016, Ivanov 2017a,b). Ivanov et al. (2014a) were then the first to explore the term in depth and define the ripple effect as resulting "from disruption propagation of an initial disruption towards other SC stages in the supply, production, and distribution networks". The ripple effect often quickly follows a singular disruption and with each new propagation the consequences worsen (Figure $1)$.
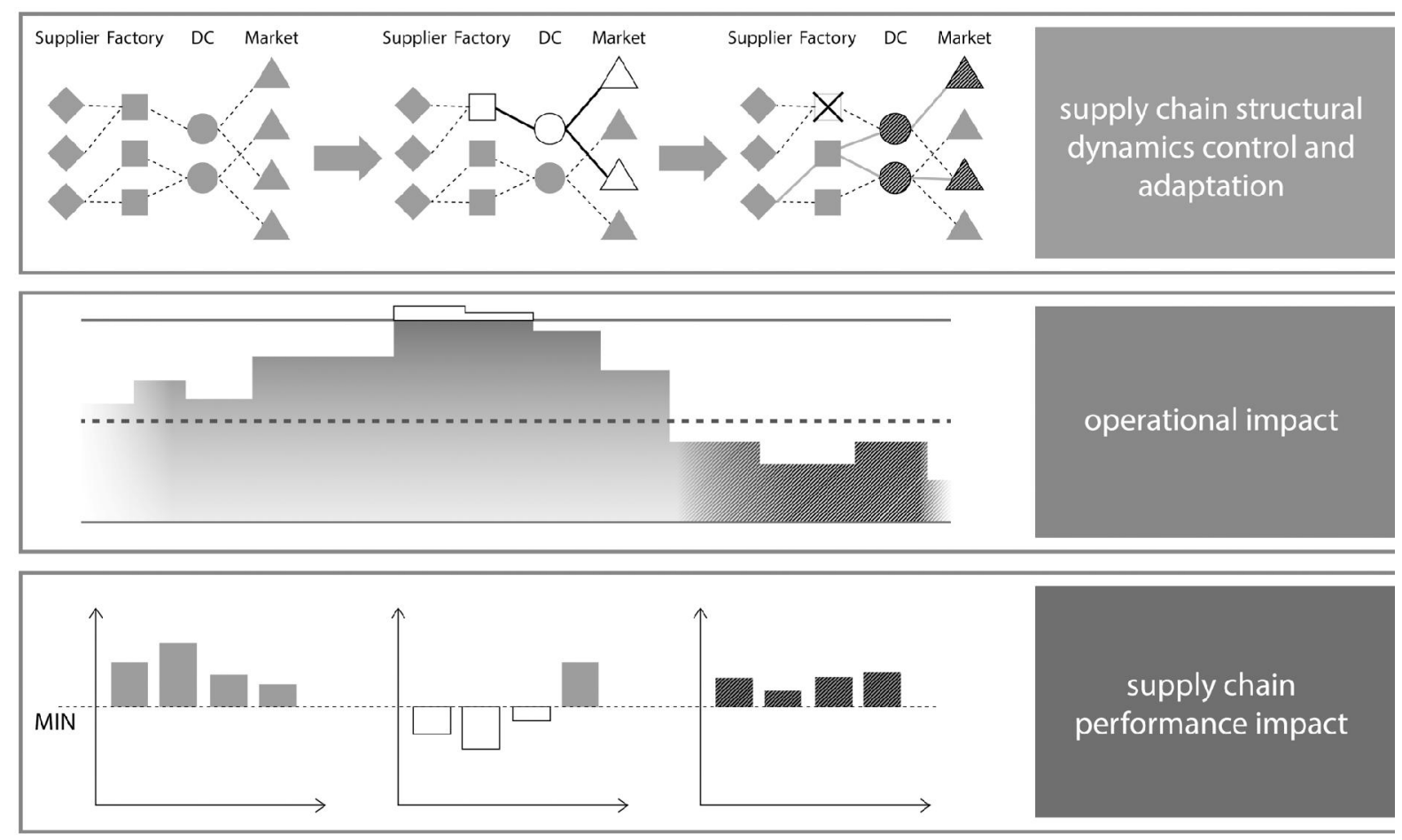

Figure 1 Disruption propagation in the SC

Differences between the bullwhip effect and the ripple effect, including frequency of risk events, disruption impact on SC performance, duration and length of recovery period and whether inventory (bullwhip) of structural (ripple) dynamics are affected, are delineated by Sokolov et al. (2016) (Figure 2). 


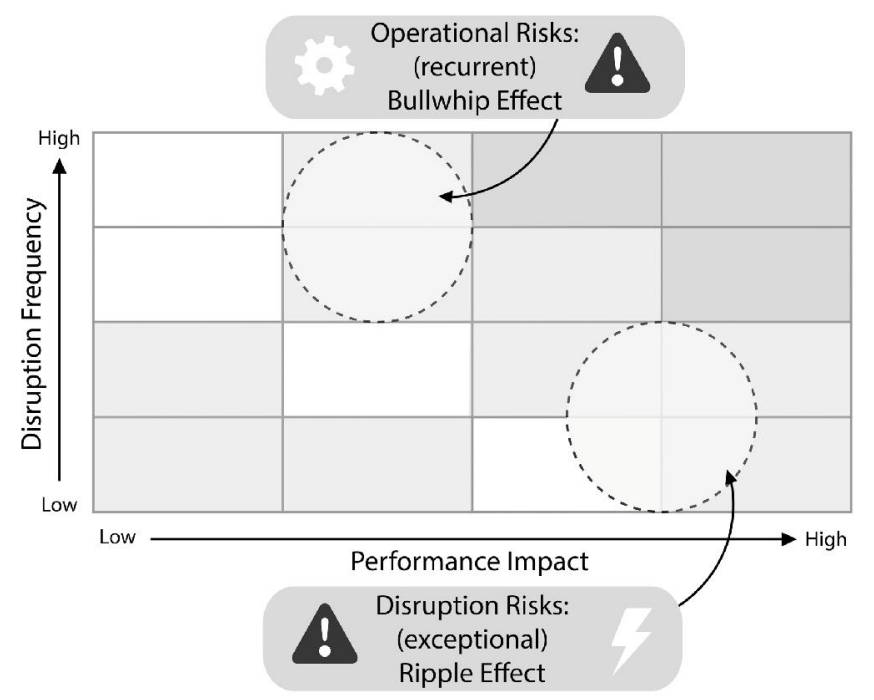

Figure 2 Bullwhip and ripple effects

In Table 1, the bullwhip and ripple effects are classified.

Table 1. Bullwhip and ripple effects in the SC

\begin{tabular}{|l|l|l|}
\hline Feature & Ripple-Effect & Bullwhip-Effect \\
\hline What uncertainty? & Hazard, deep uncertainty & Random uncertainty \\
\hline What risks? & $\begin{array}{l}\text { Disruption, exceptional risks (e.g., a } \\
\text { plant explosion) }\end{array}$ & $\begin{array}{l}\text { Operational, recurrent risks (e.g., } \\
\text { demand fluctuation) }\end{array}$ \\
\hline $\begin{array}{l}\text { What can be dis- } \\
\text { turbed? }\end{array}$ & $\begin{array}{l}\text { Structures and critical performance } \\
\text { (such as supplier unavailability or } \\
\text { revenue) }\end{array}$ & $\begin{array}{l}\text { Operational parameters such as lead- } \\
\text { time and inventory }\end{array}$ \\
\hline $\begin{array}{l}\text { How are deviations } \\
\text { prevented? }\end{array}$ & Proactive redundancy and flexibility & Information coordination \\
\hline $\begin{array}{l}\text { What happens after } \\
\text { the disturbance? }\end{array}$ & $\begin{array}{l}\text { Short-term stabilization and middle- } \\
\text { and long-term recovery; high coordi- } \\
\text { nation efforts and investments }\end{array}$ & $\begin{array}{l}\text { Short-term coordination to balance } \\
\text { demand and supply }\end{array}$ \\
\hline $\begin{array}{l}\text { What is perfor- } \\
\text { mance impact? }\end{array}$ & $\begin{array}{l}\text { Output performance can decrease, } \\
\text { such as in annual revenues or profits }\end{array}$ & $\begin{array}{l}\text { Current performance can decrease } \\
\text { such as in daily or weekly stock- } \\
\text { out/overage costs }\end{array}$ \\
\hline
\end{tabular}

This study does not pretend to be exhaustive or present some novel models of mathematical analysis. It rather aims at a pedagogical and clear explanation of the ripple effect, analysis of some major recent publications, comparison with other known effects under uncertainty and delineating research perspectives in this domain. The rest of this paper is organized as follows: Section 2 analyses recent research on the ripple effect in the SC from positions of optimization and simulation. Section 3 summarizes insights on the ripple effect reasons and mitigation. Section 4 outlines future research avenues. The paper is concluded in Section 5. 


\section{Optimization and simulation ripple effect-related research}

In the last decade, the reasons for disruptions in SCs have been extensively investigated. Numerous studies including (but not limited to) the works of Hendricks and Singhal (2005); Blackhurst et al. (2005, 2011); Klibi and Martel (2012), Simangunsong et al. (2012), Ivanov et al. (2014a,b), Ambulklar et al. (2015), Ho et al. (2015), Govindan et al. (2015b), Gunasekaran et al. (2015), Gupta et al. (2015), Tukamuhabwa et al. (2015), Ivanov et al.(2016a,b), Snyder et al. (2016), Khalili et al. (2017), Ivanov (2017a), Jain et al. (2017), Geng and Xiao (2017), Yu et al. (2017) revealed basic reasons for the disruptions and their impact on SC execution and performance. Remaining focused on quantitative methods, a review of the wealth of literature on SC risk management and collaboration strategies as well as behavioral literature is out of scope of this paper.

In existing studies, two groups of problems are typically examined: disruption consideration with and without recovery measures. The result has been that in quantitative analysis two corresponding approaches, proactive and reactive, were developed to protect the SC from disruption. The proactive approach deals with the creation of SC protections without consideration of recovery measures in SC design (Dolgui and Prodhon, 2007, Klibi et al. 2010, Dolgui et al., 2013, Aloulou et al., 2014, Snyder et al. 2016). On the other hand, reactive strategies focus on designing SC processes and structures which can be adjusted when disruption occurs. A recent survey on reactive policies for SC disruption recovery can be found in (Ivanov et al. 2017b).

\subsection{Mathematical optimization}

Mixed-integer programming (MIP) models SC design and planning constraints in terms of mathematical problems (Dolgui and Proth, 2010). The MIP models highlight the different possible impacts of disruptions on SC performance depending on the structural and planning parameters in place. Snyder and Daskin (2005) developed a model which aimed to optimize SC design by assigning customers to locations and therefore minimizing total SC costs. Lim et al. (2010) designed an MIP model with a fully reliable backup supplier. The associated recovery costs are integrated into the objective function. Li et al. (2013) furthered this model, applying limitations to the fortification budget.

Accounting for the risk of stochastic disruptions, Chen et al. (2011) devised a joint inventory location model. Considering the trade-off between under-vs over-estimations of disruption probabilities, the model developed by Lim et al. (2013) suggested that under-estimation has greater impact on SC performance and higher costs than overestimation. Accounting for inventory, backordering, available machine capacity and labour levels for each source, transportation capacity at each trans-shipment node and available warehouse space at each destination, Rafiei et al. (2013) performed an analysis of a comprehensive problem statement with multiple products and periods. The authors consider a model which analyses the situation surrounding backup suppliers with reserved capacity and backup transshipment nodes which can satisfy demands at higher prices without facility disruption. Solving the model requires priority-based genetic algorithms. 
To explore resilience in correlated disruptions, Hasani and Khosrojerdi (2016) developed an MIP model. The solution comprises a Taguchi-based memetic algorithm for customized hybrid parallel adaptive large neighborhood search. The model was developed for a global medical device manufacturer.

For quick recovery and reaction to disruption, a resilient topology of a SC was developed by Rezepour et al. (2017). Keeping emergency stock at retailers, reserving backup capacity at the suppliers and multiple sourcing are analysed by the authors using a non-linear MIP to determine which network and mitigations policies are the most profitable. The study concludes that risk mitigation policies stabilize retail prices, a benefit for customers, and better market share. In addition, the best alternative in the case of unreliable suppliers was found to be downstream "emergency stock".

Unlike MIP, stochastic programming models operate based on scenarios with parameters from a set of discrete scenarios with a given probability of occurrence. Included in the objective functions of stochastic programming is the sum of first stage performance and an expected second-stage performance. According to a formulation by Ravindran et al. (2010), the conflicting objectives of price, lead-time, and VaR-type risk of disruption must all be minimized at the same time. The solution to the model arises from goal programming. For integrated supplier selection, order quantity and customer order scheduling in the event of SC disruption, Sawik (2013) developed another stochastic programming model. For addressing supplier selection and order allocation given operational and disruption risks, Torabi et al. (2015) created a mixed two-stage stochastic programming model with a bi-objective. This model accounts for reactive strategies, e.g. using backup suppliers or having supplier continuity plans in place. Recently, Sawik (2017) conceptualized a portfolio approach to SC disruption management.

\subsection{Simulation}

The need for ripple effect analysis in the SC has been recognized and systematically considered in simulation literature with regards to risk analysis, performance impact and resilience assessment (Ivanov 2017a,b). In simulation literature, the SC ripple effect is analysed from three methodical viewpoints:

- $\quad$ system dynamics

- agent-based modelling

- discrete-event simulation.

Because simulation studies concerning the ripple effect deal with time-dependent and gradual disruption duration, duration of recovery measures and capacity degradation and recovery, they have earned an important role in academic research. In comparison with analytical closed form analysis, simulation has the advantage that it can handle complex problem settings with situational behaviour changes in the system over time. 
First, one method which has simulated the ripple effect in the SC is system dynamics. Wilson (2007) shows how fulfilment rate and inventory fluctuations are impacted by the ripple effect during transportation disruptions in multistage SCs. The results of the study point to transportation disruptions between the Tier-1 supplier and the warehouse as having the highest performance impact. For disruption mitigation, the study also details the worth of VMI (vendor-managed inventory).

Second, SC disruptions, including their performance impacts, have also been modelled using agentbased simulation. With AnyLogic multi-method simulation software, Xu et al. (2014) use this to analyse recovery policies and their corresponding impact on SC service levels in the event of disrupted supplier capacities in a SC with three stages. After comparing performance impact with and without recovery measures in four scenarios, the authors are able to conclude that the impact of the ripple effect on customer satisfaction depends on both proactive resiliency planning and recovery measures. Interestingly, the study also clearly points out that retailer-supplier links are particularly disruption sensitive.

Third, discrete-event simulation can be applied for resilience analysis in consideration of severe SC disruptions. Based on a real case study about a Portuguese automotive SC, Carvalho et al. (2012) dissect a SC with four stages to ascertain how various strategies of recovery affect SC performance during disruption. To do this, the authors compare two recovery strategies and six disruption scenarios, which differ from one another in presence or absence of a disturbance and presence or absence of a mitigation strategy. Using an ARENA-based simulation model, lead-time rations and total SC costs, as they affect performance, are analysed.

Using discrete-event simulation, Schmitt and Singh (2012) quantitatively estimate the risk of disruption for a multi-echelon SC, measuring the risk of disruption with "weeks of recovery" as a disruption amplification. Satisfying demand by using another location in the network, procuring material or transport from alternative sources or routes, and keeping inventory reserves throughout the SC are included in the model of proactive and recovery strategies. There are two primary takeaways from this for research on the ripple effect. First, increases in raw material and finished goods inventories as a prevention measure against disruptions are considerably larger than those required based on the stochastic demand, and, second, "upstream disruptions in the SC may not be felt as quickly as downstream disruptions, but their impact can be amplified, outlasting the disruptions themselves". Dependence on the employment efficiency of backup mitigation methods also become evident through this study.

Ivanov (2017a) considered a four-stage SC that comprises a manufacturer, a central distribution centre, two regional distribution centres and ten customers in different European cities. Using anyLogistix software, a discrete-event simulation model for ripple effect analysis has been developed. The results suggest that the ripple effect enhances the performance impact of disruptions. Upstream disruptions are more likely to result in ripple effects in the case of single source policy. A safety stock increase is 
be recommended at the facilities downstream of disruption-risky SC elements. Higher inventory levels in the downstream SC dampen ripple effect propagation towards the customers. At the same time, a safety stock increase at disruption-risky facilities should be considered carefully, since if these facilities are not able to perform outbound operations (e.g. fire or strike) the increased safety stock is not useful for dampening the ripple effect. Moreover, it has been observed that ripple effect has greater impact on service level and order fulfilment than disruption duration. This implies that dual sourcing at SC bottlenecks and large inventory holding points downstream of disruption-risky facilities is more important than hasty investments in quick recovery.

Ivanov (2017b) developed a discrete-event simulation model in anyLogistix to study the interfaces of the ripple effect and sustainability. A multi-stage SC with suppliers, factory, distributions centres, and customers has been considered. This study helps to identify which sustainability factors mitigate the ripple effect in the SC and which sustainability factors enhance this effect. The results indicate that (i) sustainable single sourcing enhances the ripple effect; (ii) facility fortification at major employers in regions mitigates the ripple effect and enhances sustainability; and (iii) a reduction in storage facilities in the SC downstream of a disruption-risky facility increases sustainability, but causes the ripple effect. In addition, the results depict a time lag between the recovery launch and recovery impact on service level gap reduction. This leads to the conclusion that proactive policies in the SC need to be designed with consideration of disruption durations. Moreover, the results indicate that human aspects need to be involved in regard to coordination complexity analysis and recovery impact on disruption duration. Ivanov (2017c) developed a discrete-event simulation model in anyLogistix to study the impact of demand pattern identification with the help of Big Data on ripple effect mitigation in the SC. Four managerial strategies have been proposed for different demand and inventory control patterns.

Ivanov and Rozhkov (2017) analyse the performance impacts of ordering and production control policies in the presence of capacity disruptions for the real-life example of a retail SC with product perishability considerations by using AnyLogic. The trade-off between perishability and disruption risks is handled with the help of a hybrid discrete event - agent simulation. It has been observed that a production capacity disruption causes both product shortage and write-off risks. For the first time, the effect of "postponed redundancy" has been observed concerning the impact of redundant productionordering system behaviour during the disruption period on the production-ordering system behaviour in the after-disruption period. Examples of SC redundant behaviour during the disruption period are redundant production or deliveries downstream from the disrupted part of the SC or redundant order allocations to disrupted facilities in the upstream direction. Moreover, a coordinated productionordering contingency policy in the SC within and after the disruption period has been developed and tested to reduce the negative impacts of the "postponed redundancy". The results suggest that SCs with a long cycle between order allocation and delivery are more sensitive to the negative impacts of production capacity disruptions. Furthermore, after returning to normal conditions, average inventory along with lost orders dynamics can be used as indicators of SC recovery after a disruption. Delayed 
orders are one of the system inertia indicators. If delayed orders are increasing under conditions of stabilized service levels, this indicates a significant inventory increase in the near future in the SC. The experiments provide evidence that a coordinated policy is advantageous for inventory dynamics stabilization, improvement in on-time delivery and variation reduction in customer service level.

\subsection{Control theory}

Control theoretic studies on the ripple effect take another perspective as MIP and stochastic programming representing SCs, and production-inventory-logistics policies as trajectories and feedback loops. Two streams, i.e., optimal program control and feedback control can be classified. Based on these two streams, a hybrid control-theoretic approach was developed by Ivanov et al. (2014a): this describes the ripple effect in the SC. In a multi-period, multi-commodity model SC, Ivanov et al. (2013) included the reconfiguration of transportation in the event of SC disruptions; the model combines linear programming (LP) and optimal control. Further, Ivanov et al. (2014b) design a multi-period, multicommodity SC with consideration of structure dynamics. The foundational aim of these studies is to describe the SC as a non-stationary and dynamic control system with an LP model. The authors allot static and dynamic parameters between the LP and control models.

Using a hybrid optimization-control model to simulate SC recovery policies for multiple disruptions in multiple periods in a multistage SC, Ivanov et al. (2016b) developed an approach which allows simultaneous analysis of performance impact in a simulation. In addition, by considering disruption duration and recovery costs, Ivanov et al. (2016a) further the assessment of performance impact and SC plan reconfiguration. With a SC planning model made up of aspects of control theory and linear programming, the authors evaluate seven proactive SC structures, calculate recovery policies for redirecting material flows in two scenarios of disruption and take measure of how service levels and costs impact performance. This study highlights how different parametrical and structural resilience measures impact SC service and efficiency.

In the studies of Spiegler et al. (2012, 2016), and Spiegler and Naim (2017) it is demonstrated that including non-linear dynamics nonlinearities can result in unexpected dynamic behaviours in systems of production and inventory, for example, sustained oscillation or limit cycles. This can prevent complex model simulation without preliminary analysis and assist in identifying non-linear effects. In an analysis of SC resilience, Spiegler et al. $(2012,2016)$ establish a method of using non-linear control theory in application to the empirical context of a grocery SC. In addition, the authors evaluate nonlinear control theory as a lens through which to explore the hidden dynamics of the SC. The method of Spiegler et al. produced new perspectives on the control structures of non-linear systems; this included an increased understanding of how control parameters influence dynamic behaviours and how non-linearities impact the performance of the SC.

\subsection{Complexity and reliability theory}


Nair and Vidal (2011) study SC robustness against disruptions using graph-theoretical topology analysis. They studied twenty SCs which were subjected to random demand. The performances of the SCs were evaluated by considering varying probabilities of the random failures of nodes and targeted attacks on nodes. Furthermore, the analysis of the study also included the severity of these disruptions by considering the downtime of the affected nodes. The results have been gained through multi-agent simulation. Furthermore, the authors went into detail on the impact of SC structural design on robustness in the presence of both demand and disruption uncertainty.

Graph theory was applied by Kim et al (2015) to study how SC structure impacts resilience. According to this study, network structure is an important determinant of how likely disruption is. Using indicators from graph theory in application to the propagation of disruption in multistage distribution network, Sokolov et al. (2016) were able to quantify the SC ripple effect. Taking account of disruption propagation in a connected graph, Han and Shin (2016) evaluate the structural robustness of the SC in random networks and compare this with the likelihood of network disruption resulting from random risk. The reliability of a multistage SC is evaluated by Lin et al. (2017) as the probability that market demand, and therefore sufficient commodity delivery, can be met by the SC through multiple stations of transit within the time appropriate time frame. In this study, system reliability acts as the delivery performance index, and is assessed by the number of minimal paths.

\section{Insights on ripple effect reasons and mitigation}

In this section, we summarize the lessons learned from recent research so far. We start with identification of reasons for ripple effect. Subsequently, the existing knowledge on mitigation policies is summarized. Finally, critical analysis of the application of different quantitative methods is performed.

\subsection{Reasons}

Fig. 3 summarizes major reasons and counter-measures for the ripple effect.

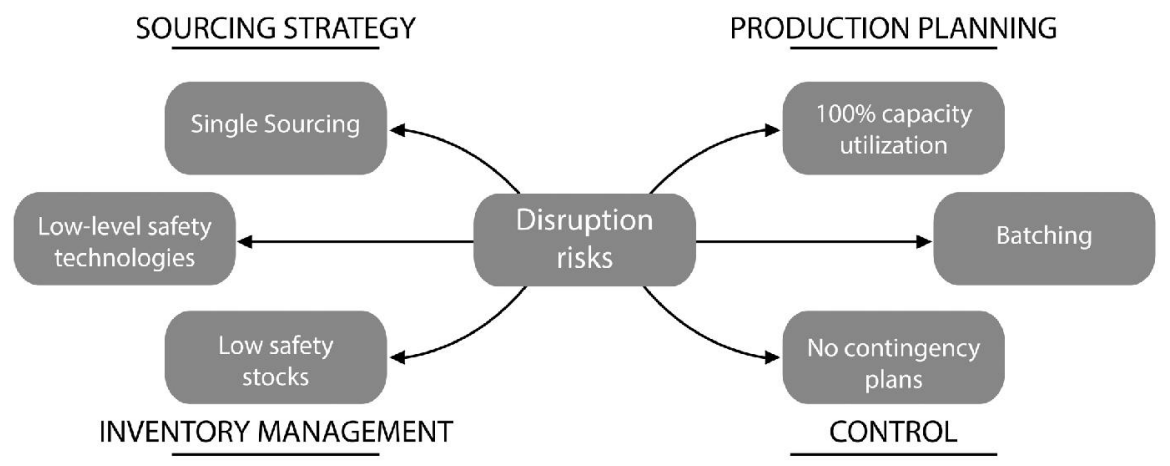

Fig. 3. Reasons for ripple effect

In the last decade, the reasons for disruption in SCs have been extensively investigated. Numerous studies revealed four basic reasons for the increase in disruption impact on SC execution and performance. 
The width of the ripple effect and how it impacts economic performance is reliant on redundancies such as inventory or capacity buffers, also called robustness reserves, and on the speed and extent of recovery measures. As a result, it is necessary that, in the proactive mode, risk and SC resilience are assessed and incorporated at the design and planning stages.

In the reactive mode, operationalization of contingency plans, such as alternative suppliers or shipping routes, must occur quickly in the control stage. This ensures quick stabilization and recovery, which is required to maintain supply continuity and prevent long term impact. In order to assess the impact of the disruption on the $\mathrm{SC}$, and both the costs and effects of material flow redirection, companies require a tool supported by collaboration and SC visibility solutions to implement these recovery policies.

\subsection{Mitigation policies for the ripple effect}

The resilient SC requires two critical capacities: resistance and recovery. For resistance, which is the SC's ability to protect against disruptions and reduce impact once the disruption occurs, some redundancy such as backup sourcing, risk mitigation inventory or capacity flexibility must be built at the proactive stage. For recovery, this redundancy must be used jointly with reactive contingency plans (Fig. 4).

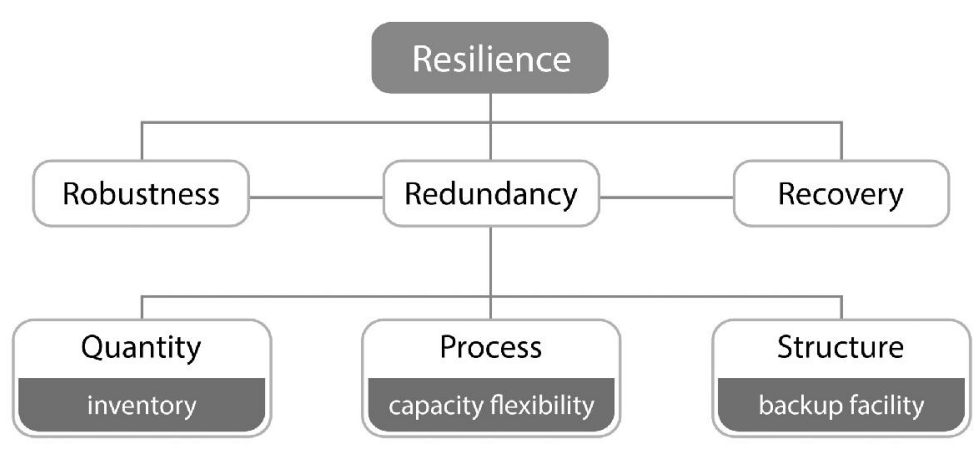

Fig. 4. Resilience concept

Recall the BASF example from the introduction. BASF built a resilient SC, which is why the economic consequences of the afore-mentioned incident were considerably smaller than expected (BASF 2017). BASF took process safety and risk prevention measures that included globally valid guidelines and requirements for buildings etc. and practical security trainings for employees and support staff. Along with process safety and risk prevention measures, BASF has global emergency response management. This management consists of the integration of worldwide group companies, joint ventures, partners, suppliers and customers. Emergency phones and an integrated network of control centres (e.g. internal/external fire departments and rescue service) also enable this global emergency response management to work even more closely together. BASF was prepared for the incident in October 2016, but there is still long-term impact mainly because of the integrated Verbundsystem and the ripple effect which has resulted from it. 
Agile and resilient practices of a firm do significantly influence its SC performance and determine its competitiveness in the market. Details of methodologies across the works on SC robustness, flexibility, and resilience differ. A classification of relevant operability objectives can be found in (Ivanov and Sokolov 2013). By introducing performance in disruption analysis, robustness, or the ability of a system to maintain current performance and output up to a certain standard, is typically called into question since it must cover a broad scope of uncertainties. A SC that is able to meet planned performance expectations despite disruption is considered robust. A robust SC is not affect negatively by disruption.

$\mathrm{SC}$ robustness is linked with resistance and redundancy. A second property of the SC involves whether planned execution and performance can be maintained, executed and recovered (or adapted, but still acceptable) in the event of disruption: this is referred to a SC resilience. The resilience of SCs is a property which involves the ability of the SC to change itself quickly, structurally and functionally depending on the current execution state, while simultaneously reaching SC management goals through a change in SC structures and behaviour. Our understanding of resilience is that it is based on redundancy, which ensures both robustness and flexibility. In this setting, flexibility is a system's ability to adjust and change processes and structures according to the situation as a reaction to internal and external disturbances. In Fig. 5, we summarize the relationships between redundancy, robustness, flexibility and resilience.

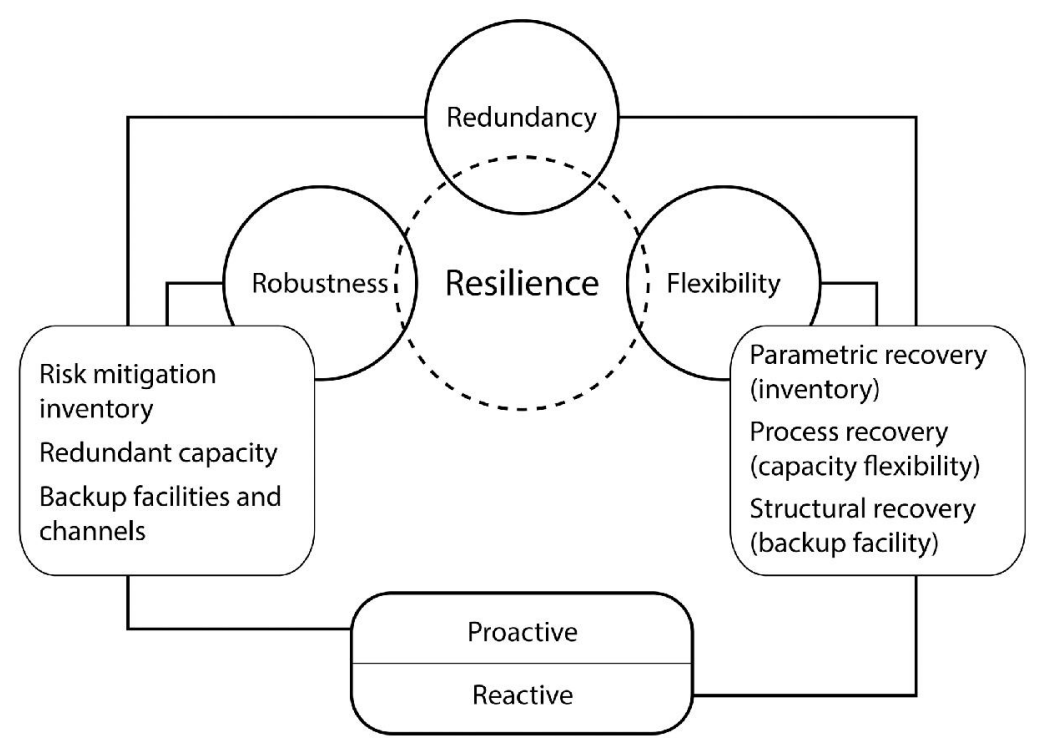

Fig. 5. Ripple effect control elements

Robustness is meant as a more or less direct usage of redundancy (e.g., using redundant inventory to cope with production capacity disruptions). Flexibility considers indirect usage of redundancy in terms of changing the system behavior by re-allocating inventories, capacities and sourcing facilities in the SCs. Different reserves (risk mitigation inventory, capacities, backup suppliers) can be referred to as redundancy. It is important to note that risk mitigation inventory differs from classical safety stock and 
is considered separate from the disruptive risks. For this issue, valuable approaches and models for SC design and planning under uncertainty were elaborated.

Second, new strategies of system flexibility such as leagile, agile and responsive SCs can be applied to make SCs more flexible in a wider sense of the word. System flexibility is also related to better coordination in SCs and refers to concepts like collaborative planning, forecasting and replenishment. Fourth, a set of postponed decisions based on process and product flexibility (product postponement, rolling/adaptive planning) can be used. All these approaches can be referred to as SC flexibility.

Redundancy and flexibility generally serve for two problem areas. First, they are intended to protect the SC against perturbation impacts based on certain reserves. This issue is related to SC robustness. Second, redundancies are created to amplify the fork variety of SC paths to react quickly and flexibly to changes in a real execution environment. This issue is related to $\mathrm{SC}$ resilience. $\mathrm{SC}$ resilience is therefore a complex characteristic of a non-failure operation, durability, recoverability, and the maintenance of SC processes and the SC as a whole. This is connected with the creation of an adaptation system (with regard to operations and resources) for the prevention, improvement or acquisition of new characteristics for the achievement of goals under the current environmental conditions varying in time.

Various methods have been identified in recent literature for strengthening SCs in terms of their ability to mitigate the impact of uncertainty and maintain robustness through material inventory, capacity buffers et. Approaches and models for designing and planning SCs under uncertainty have been developed, though proactive and reactive SCs both carry some costs.

By increasing redundancy, such as inventory increases, preparing additional production capacity, alternative transportation etc., costs are also increased. Yet, these redundancies can also lead to increased sales and service levels. In addition, elements of robustness, which facilitate schedule execution, also lower the risk of disruptions. As a result, achieving targets such as on-time delivery can be more easily accomplished - which, like redundancies, also positively influences sales and service levels. Redundancy in the SC may also correspondingly improve flexibility and positively affect service level and costs.

Building a resilient SC means finding a balance of robustness and flexibility. In the event of a disruption, this will allow the highest level of service possible, and paid for by the upfront costs of redundancy. SC flexibility and robustness are connected through adaptation. Through the lens of dynamics, elements of robustness can also be considered elements of flexibility, while elements of flexibility can be simultaneously considered drivers of robustness. Both elements act as SC "uncertainty cushions". In terms of risk covering and SC management strategies, different combinations of service level, costs and stability, with elements of flexibility and robustness in proactive and reactive control loops, can be evaluated. 
Generally we aim to explore the how these different combinations of disruption scenarios, proactive mitigation strategies and reactive recovery policies impact SC performance. Costs and service levels may be impacted differently by different aggregates of proactive mitigation (e.g. higher risk mitigation inventory) and reactive recovery (e.g. backup facility) strategies, and alternate disruption scenarios. Deciding which of the policies to adopt is the task of quantitative analysis.

\subsection{Quantitative analysis methods evaluation}

With the help of optimization and simulation approaches, current research generates new knowledge about the influence of disruption propagation on SC output performance considering disruption location, duration, and propagation and recovery policies.

Though MIP models produce notable insights for managers and can be applied where the probability of disruption can be roughly estimated, the majority of MIP solutions recommend opening new facilities. Even if transportation costs are maintained, total costs increase. However, predicting factory fires, natural disasters, or piracy in some locations is nearly impossible. Because of this, focus should be placed on mitigation strategies and identifying disruption impact on finances and operation no matter where or how the disruption started. Further, existing studies generally fail to adequately consider the dynamics of SC execution: disruptions are considered static events regardless of duration or stabilization and recovery policies. Like MIP, by assuming known reliability for suppliers and parametric probabilities, the stochastic programming models are also difficult to actuate. The number of variables and constraints are exponentially increased in approaches based on scenarios.

In sum, paying to protect the SC before disruption happens can prevent many problems in the future, though it is important to note that disruptions cannot be avoided completely. Recovery policies should be the center of focus regardless of the type or origin or the disruption. Adaptation is necessary for achieving desired output performance by ensuring the possibility to change SC plans and inventory policies. In this context, the ultimate robustness and stability of the SC depends on the decisions taken spontaneously by decision-makers (this differs, for example, from the natural laws which govern a pendulum, which returns to its initial state without adaptation after disruption). Adaptation, particularly human-coordinated adaptation, in the SC is the necessary precursor of stability and robustness (Ivanov and Sokolov, 2013).

Many useful methods from management science, operations research and system dynamic and control theories can be applied for analyzing and mitigating the ripple effect. Different problems need different solutions, and no one technique can be universally applied to the same effect. Mathematical and stochastic optimization is best applied at the stages of SC design and planning, rather than focused on the dynamic behaviour of the SC. Strategic SC design and tactical plans for SC performance during the execution and recovery stages is improved through models created from the dynamics of the execution processes. 
Reactive approaches can be implemented in three ways: as pure recovery policies without proactive protection, as integrated parts in proactive approaches, or as integrated parts with proactive approaches. Here, integration in proactive approaches will be the focus. Reactive elements are often found in proactive techniques. If primary suppliers are disrupted, MIP models with facility fortifications might shift product to backup suppliers. A rolling, planning policy is implemented in a model predictive control model, and includes re-planning elements. Policies for recovery are also suggested by inventory control models. In the case of disruption, SC managers can use simulation techniques that consider "what-if" scenarios to expedite the estimation of recovery policies and understand how operations and finances will be impacted.

Naturally, simulation is used to study disruption propagation and the ripple effect in the SC, and existing studies account for time and length of disruption in recovery policies. In regards to parametrical and structural resilience levers such as capacity levels, inventory control policies, dual sourcing, and backup facilities, a sensitivity analysis for SC performance output must be performed in the future. This analysis would illuminate important proactive and reactive decision-making support processes and models concerning severity of disruption, recovery policies, and resilience levers as they are implemented singularly or in combination to address disruption propagation in the SC. This might provide new avenues or methods to estimate the impact of potential disruptions in the proactive stage and actual disruptions in the execution stage, while generating efficient and effective stabilization and recovery measures.

The primary challenge in this area is the extension of resilience strategies and the provision of appropriate disruption protections without lessening the effectiveness of the normal SC. The costs redundancy and adaptation must also be taken into account. Research in the proactive and reactive domains has been limited, but this is an opportunity for future research. Visualizing these processes through simulation has not yet been done extensively to model the ripple effect in the supply chain. For this, simulation models can improve tools which are already used in developing SC agility and visibility in terms of disruption velocity.

\subsection{Summary of the ripple effect reasons and countermeasures}

Table 2 summarizes reasons for the ripple effect and counter-measures

Table 2 Ripple effect reasons and countermeasures

\begin{tabular}{|c|c|c|c|}
\hline Reason & SCM impact & Ripple effect impact & Countermeasures \\
\hline \multirow[t]{3}{*}{ Leanness } & Single Sourcing & \multirow{3}{*}{$\begin{array}{l}\text { In the non-disrupted scenario, it } \\
\text { is irrational to avoid lean prac- } \\
\text { tices. At the same time, a capaci- } \\
\text { ty disruption may result in the } \\
\text { ripple effect and performance } \\
\text { decrease. Recommendation to } \\
\text { use capacity buffers or a backup } \\
\text { facility as additional capacity }\end{array}$} & $\begin{array}{l}\text { Multiple / Dual sourcing } \\
\text { / Backup suppliers }\end{array}$ \\
\hline & Low inventory & & Risk mitigation inventory \\
\hline & Inflexible capacity & & Postponement \\
\hline
\end{tabular}




\begin{tabular}{|c|c|c|c|}
\hline & & reserves. & \\
\hline \multirow[t]{3}{*}{ Complexity } & Globalization & \multirow{3}{*}{$\begin{array}{l}\text { Without a coordinated contin- } \\
\text { gency policy, disruption recov- } \\
\text { ery and performance impact } \\
\text { estimation can be very long last- } \\
\text { ing and expensive. Coordinated } \\
\text { control algorithms are needed to } \\
\text { monitor SC behaviour, identify } \\
\text { disruptions and adjust order } \\
\text { allocation rules using a coordi- } \\
\text { nated contingency policy. }\end{array}$} & $\begin{array}{ll}\text { Geographical sourcing } \\
\text { diversification }\end{array}$ \\
\hline & Decentralization & & $\begin{array}{l}\text { Global SC contingency } \\
\text { plans }\end{array}$ \\
\hline & Multi-stage SCs & & $\begin{array}{l}\text { Supplier } \\
\text { according to disruption } \\
\text { risks }\end{array}$ \\
\hline
\end{tabular}

First, literature provides evidence that disruption duration and propagation impact SC performance. Second, proactive strategies such as backup facilities and inventory have positive impacts concerning both performance and prevention of disruption propagation. Third, speed of recovery plays an important role in mitigating the performance impact of disruptions. Fourth, an increase in SC resilience implies significant cost increases in the SC.

\section{Future research avenues}

\subsection{Experimental settings and managerial insights}

Typically, the duration of a disruption has been modelled without clearly integrating dynamic recovery time and costs. The research domain is dominated by the performance analysis of how supplier failure probabilities are used. Simultaneously, with regard to service level and costs, developments surrounding disruption propagation and SC design survivability are still in the beginning phases. How recovery policies are implemented must be evaluated further.

The ripple effect analysis in the SC is expected to furnish fresh insights for management regarding the following questions:

- In what circumstance does one failure cause other failures?

- Which structures of the SC are especially susceptible to the ripple/domino effect?

- What are the typical ripple effect scenarios and what is the most efficient way to respond them?

Given these reflections, other ways to apply quantitative analysis to ripple effect modelling arise. Several research gaps might be addressed by the ability to dynamically change parameters during experiments and to observe how these changes impact performance in real time, e.g. considering:

- disruption propagation in the SC;

- dynamic recovery policies;

- gradual capacity degradation and recovery;

- multiple performance impact dimensions including financial, service level and operational performance.

\subsection{Empirical research and simulation}


Even if simulation and optimization studies provide valuable insights on preventing and mitigating the ripple effect in the SC, there is a lack of practical validation. Only a few studies incorporated real company data. At the same time, empirical research in SC management has also developed a variety of valuable approaches and methods to tackle the ripple effect. In this setting, combined empiricalsimulation, studies are encouraged. An example of an area for such integrated research are coordinated contingency plans. In addition, identification of information patterns needed to make decisions on ripple effect identification and recovery policies would be in the scope of this research.

\subsection{Digital supply chains and smart operations}

The even increasing role of information technology in SC management needs to be properly incorporated into the ripple effect research agenda. At the proactive level, advanced planning and scheduling and early warning systems are used at the preparedness stage. Decision-making at the reactive level in the case of deviations and structural dynamics is concerned with SC control and adaptation in different uncertainty environments where response and recovery are needed to figure out how to best allocate scarce resources to rebuild/reconnect SCs to ensure process continuity and viability. Feedback control can be supported by RFID (radio-frequency identification) technology (Dolgui and Proth, 2010) and supply chain event management systems which can be used to effectively communicate these disruptions to the other tiers, and help revise initial schedules. In practice, new cloud-based analytics platforms such as Resilience 360 at DHL allow comprehensive disruption risk management by mapping end-to-end SC, building risk profiles and identifying critical hotspots in order to initiate mitigation activities and alert in near-real time mode on incidents that could disrupt the SC.

On the engineering technology side, the ongoing developments such as Industry 4.0, additive manufacturing, smart sensors and intelligent materials open opportunities, but also create new challenges for ripple effect analysis in the SC. Examples of the impacts of new engineering technologies on the $\mathrm{SC}$ are the localization of production, high flexibility, and reduced SC complexity. This may positively influence ripple effect mitigation. At the same time, disruptions in the information systems and the networked cloud-based digital SC environment itself need to be considered. This aspect clearly presents a research gap.

\subsection{Complexity theory, dynamics, and control}

For dealing with the ripple effect in the SC, complexity management and system modelling might provide a theoretical basis. Based on Ashby's principle of requisite variety, the problem of a system under control and uncertainty implies an area under control and area under uncertainty, according to the perspective of complexity management. The system control can be adapted by widening one area and narrowing the other (Ivanov and Sokolov 2010). Therefore, the connection between the system and the environmental spaces are categorized according to amplification of control variety or attenuation of environmental variety. A balance of control and disruption impact, and maintenance of planned execution processes and a cost efficient, fast recovery post-disruption can be achieved by amplifying the variety of the control area and reducing the area of uncertainty. Further research can be initiated in 
this area as it regards structural network properties and the identification of structural patterns in SC design which cause a greater or lesser ripple effect. In addition, the ripple effect and the impact of recovery and proactive strategies within one feedback framework including planning and adaptation control loops are revealed by applying methods of dynamic control theory.

\subsection{Key performance indicators}

Analysis of short-term and long-term impacts of the ripple effect on the SC and the creation of a performance measurement system is a promising research avenue. Even though some key performance indicators have been presented in literature episodically, there is a lack of systematic performance management techniques for the ripple effect in the SC.

\subsection{Disruptions and perishable products}

Generally, inventory constitutes a SC resilience drive in literature. In the case of SCs for perishable products, there are limits to inventory holding durations because of the short storage and expiration periods. The resilience of these kinds of SCs may be affected by the risk of goods write-off and customer segmentation by requirements for freshness. Safety stock reductions and an increase in transport frequency result from the constraints inherent with product perishability. However, when disruption risks are considered this may lead to an increase in safety stock. The bounded capacity of suppliers should also be analysed. Since customer demand tends to be vulnerable, there might be different requirements for freshness of products and penalties when product is unavailable or freshness is decreased. Further, in perishable product SCs, issues of batching usually carry more weight.

\subsection{Competition and behavioral aspects}

Since severe disruptions may influence competition in the markets, research agenda on the ripple effect needs to include this factor. In addition, managerial decisions are of a behavioral nature and subject to individual risk perceptions. Agent-based modelling can be applied to a broader scope of these problems. These principles may include collaboration (trust and information sharing) and a SC risk management culture (e.g. leadership and risk-averse behaviour). In this setting, agent-based modelling would be a suitable method for enhancing the existing simulation impact on SC ripple effect research in regard to non-engineering $\mathrm{SC}$ resilience principles.

\subsection{Ripple effect visualization}

Visualizing the ripple effect is an obvious next step for simulation features. Yet, it has not been very frequently used for modelling the ripple effect in the SC. Given this, simulation models would enhance the existing tools in SC agility and visibility concerning disruption velocity.

\subsection{Closed-loop SCs, sustainability, and humanitarian logistics}

Resilience has a number of intersections with SC sustainability. Since SCs have become more and more global, these network structures build the backbone of the modern economy and directly influence such sustainability issues as employment rates, natural resource consumption, etc. SC sustainability issues include an assessment of SC design resilience and efficient SC structure reconfiguration in the case of disruptions from the perspectives of environmental, political, and society impacts. 
Disruptions in the reverse part of closed-loop SCs, as well as disruption-based reverse logistics flows have rarely been analysed (Giandesello et al. 2017, Ivanov et al. 2017 c). Approaches for analysing the disruptions in the reverse part of the closed-loop SCs (e.g., a temporary unavailability of a warehouse for collecting the used batteries for electric cars) in regard to (i) their impact on overall SC performance as well as to (ii) proactive and reactive policies with consideration of inventory control policies and sustainable manufacturing concepts are yet to be developed. In addition, disruptions in a region frequently result in both humanitarian catastrophe and industrial disruptions at the same time. In this setting, limited resources need to be fairly allocated to both human life rescue and the stabilization of everyday life and recovery of the industrial sector.

\subsection{Human aspects}

Finally, yet importantly - the area of human factors needs to be developed in future. Our perception (partially derived from the experiments and literature) is that in a short-term perspective, SC adaptability to the disrupted mode is low and recovery actions are at the beginning of their implementation, which causes high coordination efforts. This means a very stressful time for SC recovery teams. It follows that the better the preparation, the less stressful and the more efficient the recovery work will be.

\section{Conclusion}

In this study, the ripple effect in the SC has been analysed. We delineated major features of the ripple effect as compared to bullwhip effect. The differences can be seen in regard to frequency of risk events, their impact on SC performance, duration and scope of recovery period, as well as in inventory dynamics (i.e. the bullwhip effect) vs structural dynamics (i.e. the ripple effect). Subsequently, we analysed recent quantitative literature that tackled the ripple effect explicitly or implicitly. The literature has been classified into mathematical optimization, simulation, control theoretic, and complexity and reliability research.

We observed the causes and mitigation strategies for the ripple effect in the SC. Most frequently, fires at distribution centres, tsunami and floods leading to production facility disruptions, legal conflicts between suppliers, and strikes at airlines and railway companies cause the ripple effect. The severity of the ripple effect depends both on proactive and reactive actions. Single sourcing, low inventory, inflexible and non-reconfigurable production systems, lack of contingency plans, and lack of shipment security systems may aggravate the ripple effect. Mitigation of the ripple effect becomes possible with the help of backup or dual sourcing policies, flexible and reconfigurable production and logistics systems, risk mitigation inventory, coordinated contingency policies, and physical security technologies. Generally, leanness and complexity of the SCs predominantly influence the ripple effect control framework, which includes redundancy, flexibility and resilience analysis.

Even if a variety of valuable insights has been developed in the said area in recent years, some crucial research avenues can be identified for the near future. These avenues include extension to experimental settings and managerial implications; the combination of empirical research and simulation; the 
role of SC digitalization, complexity theory, dynamics and control; performance management systems for SC disruption management; trade-offs of product perishability and disruption risks; competition and behavioral aspects of management decisions; ripple effect visualization; closed-loop SCs, sustainability and the ripple effect; as well as the incorporation of human factors in ripple effect analysis.

\section{References}

Aloulou M.A., Dolgui A., Kovalyov M.Y. (2014). A bibliography of non-deterministic lot-sizing models, International Journal of Production Research, 52(8), 2293-2310.

BASF (2017). https://www.basf.com/de/de/company/sustainability/environment/safety.html (20.06.17)

Behzadi, G., M.J. O’Sullivan, T.L. Olsen \& A. Zhang (2017). Allocation flexibility for agribusiness supply chains under market demand disruption. International Journal of Production Research, DOI: 10.1080/00207543.2017.1349955.

Blackhurst, J., Craighead, C.W., Elkins D., and Handfield, R. (2005). An empirically derived agenda of critical research issues for managing supply-chain disruptions. International Journal of Production Research, 43(19), 4067-4081.

Blackhurst, J., K. S. Dunn, and C. W. Craighead. (2011). An empirically derived framework of global supply resiliency. Journal of Business Logistics 32(4): 374-391.

Carvalho, H., Barroso, A.P., Machado, V.H., Azevedo, S., \& Cruz-Machado, V. (2012). Supply chain redesign for resilience using simulation. Computers \& Industrial Engineering, 62(1), 329-341.

Chazan, G. (2016): One person dies in blast at BASF chemicals site. In: Financial Times (17.10.16)

Choi, T.M., T.C.E. Cheng, X. Zhao. (2016). Multi-Methodological Research in Operations Management. Production and Operations Management, 25, 379-389..

Chopra, S., \& Sodhi, M.S. (2014). Reducing the risk of supply chain disruptions. MIT Sloan Management Review, 55(3), 73-80.

Dolgui A., Ben Ammar O., Hnaien F., and Louly M.-A. (2013). A state of the art on supply planning and inventory control under lead time uncertainty, Studies in Informatics and Control, 22(3), 255268.

Dolgui A., Prodhon C. (2007). Supply planning under uncertainties in MRP environments: a state of the art, Annual Reviews in Control, 31, 269-279.

Dolgui, A., \& Proth, J.M. (2010). Supply chain engineering: Useful methods and techniques, Springer: London.

FAZ (2016): Spurensuche bei BASF. In: Frankfurter Allgemeine Zeitung (18.10.16)

Geng L., Xiao R. (2017). Outer synchronization and parameter identification approach to the resilient recovery of supply network with uncertainty. Physica A: Statistical Mechanics and its Applications, 482. 407-421.

Gianesello P., Ivanov D., Battini D. (2017). Closed-loop supply chain simulation with disruption considerations: A case-study on Tesla. International Journal of Inventory Research, accepted.

Govindan, K., Jafarian, A., Azbari, M. E. \& Choi, T. M. (2016). Optimal Bi-Objective Redundancy Allocation for Systems Reliability and Risk Management. IEEE Transactions on Cybernetics, 46(8), 1735 - 1748.

Govindan, K., Soleimani, H., \& Kannan, D. (2015a). Reverse logistics and closed-loop supply chain: A comprehensive review to explore the future. European Journal of Operational Research, 240(3), 603-626.

Gunasekaran A., Subramanian H., Rahman S. (2015). Supply chain resilience: role of complexities and strategies. International Journal of Production Research, 53(22), 6809-6819.

Gupta W., He B., Sethi S.P. (2015). Contingent sourcing under supply disruption and competition. International Journal of Production Research, 53(10), 3006-3027. 
Han J., Shin K.S. (2016). Evaluation mechanism for structural robustness of supply chain considering disruption propagation. International Journal of Production Research 54(1), 135-151.

Hasani, A., Khosrojerdi A. (2016). Robust global supply chain network design under disruption and uncertainty considering resilience strategies: A parallel memetic algorithm for a real-life case study. Transportation Research Part E: Logistics and Transportation Review, 87, $20-52$.

Hendricks, K.B., and Singhal V. R. (2005). Association between supply chain glitches and operating performance. Management Science, 51(5), 695-711.

Ho, W., Zheng T., Yildiz H. \& Talluri S. (2015). Supply chain risk management: a literature review. International Journal of Production Research, 53(16), 5031-5069.

Ivanov D. (2017a). Simulation-based ripple effect modelling in the supply chain. International Journal of Production Research, 55(7), 2083-2101.

Ivanov D. (2017b). Revealing interfaces of supply chain resilience and sustainability: a simulation study. International Journal of Production Research, DOI:10.1080/00207543.2017.1343507

Ivanov D. (2017c). Simulation-based single vs dual sourcing analysis in the supply chain with consideration of capacity disruptions, Big Data and demand patterns. International Journal of Integrated Supply Management, 11(1), 24-43.

Ivanov D., and Sokolov B. (2013). Control and system-theoretic identification of the supply chain dynamics domain for planning, analysis, and adaptation of performance under uncertainty. European Journal of Operational Research, 224(2), 313-323.

Ivanov D., Pavlov A., Pavlov D., Sokolov B. (2017c). Minimization of disruption-related return flows in the supply chain, International Journal of Production Economics, 183, 503-513.

Ivanov D., Rozhkov M. (2017). Coordination of production and ordering policies under capacity disruption and product write-off risk: An analytical study with real-data based simulations of a fast moving consumer goods company. Annals of Operations Research, accepted.

Ivanov D., Sokolov B., Dolgui A. (2014a). The Ripple effect in supply chains: trade-off 'efficiencyflexibility-resilience' in disruption management, International Journal of Production Research, 52(7), 2154-2172.

Ivanov D., Sokolov B., Dolgui A., Solovyeva I., and Jie F. (2016b). Dynamic recovery policies for time-critical supply chains under conditions of ripple effect. International Journal of Production Research, 54(23), 3397-3413.

Ivanov D., Sokolov B., Pavlov A., Dolgui A., and Pavlov D. (2016a). Disruption-driven supply chain (re)-planning and performance impact assessment with consideration of pro-active and recovery policies. Transportation Research: Part E, 90, 7-24.

Ivanov D., Sokolov B., Pavlov, A. (2013). Dual problem formulation and its application to optimal redesign of an integrated production-distribution network with structure dynamics and ripple effect considerations, International Journal of Production Research, 51(18), 5386-5403.

Ivanov D., Sokolov, B. (2010). Adaptive Supply Chain Management, London et al., Springer.

Ivanov D., Sokolov, B., \& Pavlov, A. (2014b). Optimal distribution (re)planning in a centralized multi-stage network under conditions of ripple effect and structure dynamics. European Journal of Operational Research, 237(2), 758-770.

Ivanov D., Tsipoulanidis A., Schönberger J. (2017a). Global Supply Chain and Operations Management, Springer, 1st Ed.

Ivanov, D. (2018). Structural Dynamics in Supply Chain Risk Management. Springer, New York, to appear.

Ivanov, D., Dolgui A., Sokolov B., Ivanova M. (2017b). Literature review on disruption recovery in the supply chain. International Journal of Production Research, 55(20), 6158-6174.

Ivanov, D., Hartl, R., Dolgui, A., Pavlov, A., Sokolov, B. (2015). Integration of aggregate distribution and dynamic transportation planning in a supply chain with capacity disruption and the Ripple effect consideration, International Journal of Production Research, 53(23), 6963-6979. 
Jain, V., S. Kumar, U. Soni \& C. Chandra (2017). Supply chain resilience: model development and empirical analysis. International Journal of Production Research, DOI: 10.1080/00207543.2017.1349947.

Kamalahmadi M. \& Mellat-Parast M. (2016) Developing a resilient supply chain through supplier flexibility and reliability assessment, Int J Prod Research, 54:1, 302-321.

Khalili SM., F. Jolai \& S.A. Torabi (2017). Integrated production-distribution planning in twoechelon systems: a resilience view. International Journal of Production Research, 55(4), 10401064.

Kim Y., Chen Y.S., Linderman K. (2015). Supply network disruption and resilience: A network structural perspective. Journal of Operations Management, 33-34, 43-59.

Klibi W., \& Martel A. (2012). Modeling approaches for the design of resilient supply networks under disruptions. International Journal of Production Economics, 135 (2), 882-898.

Li Q., Zeng B., and Savachkin A. (2013). Reliable facility location design under disruptions. Computers \& Operations Research, 40(4): 901-909.

Liberatore F, Scaparra M.P., Daskin M.S. (2012). Hedging against disruptions with ripple effects in location analysis. Omega, 40, 21-30

Lim M., Daskin M. S., Bassamboo A., and Chopra S. (2010). A facility reliability problem: Formulation, properties and algorithm. Naval Research Logistics, 57(1), 58-70.

Lim M.K., Bassamboo A., Chopra S., and Daskin M. S. (2013). Facility location decisions with random disruptions and imperfect estimation. Manufacturing and Service Operations Management, 15(2), 239-249.

Lin Y.K., Huang, C.F., Liao Y.-C. \& Yeh, C.T. (2017). System reliability for a multistate intermodal logistics network with time windows. International Journal of Production Research, in press.

Matthews S. / Sachgau, O. (2016): BASF Faces Prolonged Shut-Down After Chemical Site Explosion. In: Bloomberg (17.10.16)

Mizgier K. J. (2017) Global sensitivity analysis and aggregation of risk in multi-product supply chain networks, International Journal of Production Research, 55(1), 130-144.

Nair A. \& Vidal J. M. (2011). Supply network topology and robustness against disruptions: An investigation using multiagent model. International Journal of Production Research, 49(5), 1391-1404.

Quang HT \& Hara Y. (2017): Risks and performance in supply chain: the push effect, Int J Prod Res, DOI: $10.1080 / 00207543.2017 .1363429$

Rafiei M., Mohammadi M., and Torabi S. (2013). Reliable multi period multi product supply chain design with facility disruption. Decision Science Letters 2(2): 81-94.

Ravindran A., Bilsel R. U., Wadhwa V., and Yang T. (2010). Risk adjusted multicriteria supplier selection models with applications. International Journal of Production Research, 48(2), 405-424.

Rezapour, S., Farahani, R., and Pourakbar, M. (2017). Resilient supply chain network design under competition: a case study. European Journal of Operational Research, 259(3), 1017-1035.

Sawik T. (2013). Integrated selection of suppliers and scheduling of customer orders in the presence of supply chain disruption risks. International Journal of Production Research, 51(23-24), 70067022.

Sawik T. (2016). On the risk-averse optimization of service level in a supply chain under disruption risks. International Journal of Production Research, 54(1), 98-113.

Sawik T. (2017). A portfolio approach to supply chain disruption management. International Journal of Production Research, 55(7), 1970-1991.

Scheibe K.P., \& Blackhurst, J. (2017). Supply chain disruption propagation: a systemic risk and normal accident theory perspective. International Journal of Production Research, DOI: 10.1080/00207543.2017.1355123

Schmitt A.J., \& Singh M. (2012). A quantitative analysis of disruption risk in a multi-echelon supply chain. International Journal of Production Economics, 139(1), 23-32. 
Simangunsong E., Hendry L. C., and Stevenson M. (2012). Supply-chain uncertainty: A review and theoretical foundation for future research. International Journal of Production Research, 50(16), 4493-4523.

Simchi-Levi D., Schmidt W., Wei Y., Zhang P.Y., Combs K., Ge Y., Gusikhin O., Sander M., Zhang D. (2015) Identifying Risks and Mitigating Disruptions in the Automotive Supply Chain. Interfaces, 45(5), 375-390.

Snyder L V., Zümbül A., Peng P., Ying R., Schmitt A. J., and Sinsoysal B. (2016). OR/MS Models for Supply Chain Disruptions: A Review. IIE Transactions, 48(2), 89-109.

Snyder L.V., and Daskin M. S. (2005). Reliability models for facility location: The expected failure cost case. Transportation Science, 39, 400-416.

Sokolov B., Ivanov D., Dolgui A., Pavlov A. (2016). Structural quantification of the ripple effect in the supply chain. International Journal of Production Research, 54(1), 152-169.

Spiegler V., Naim M. and Wikner J. (2012). A control engineering approach to the assessment of supply chain resilience. International Journal of Production Research, 50, 6162-6187.

Spiegler V.L.M. and Naim M. (2017) Investigating sustained oscillations in nonlinear production and inventory control models. European Journal of Operational Research, 261(2), 572-583.

Spiegler V.L.M., Potter A.T., Naim M.M. \& Towill D.R. (2016). The value of nonlinear control theory in investigating the underlying dynamics and resilience of a grocery supply chain. International Journal of Production Research, 54(1), 265-286.

SWR 2017. BASF geht zuversichtlich ins neue Jahr. http://www.swr.de/swraktuell/rp/bilanz-fuergeschaeftsjahr-2016-basf-geht-zuversichtlich-ins-neue-jahr/-

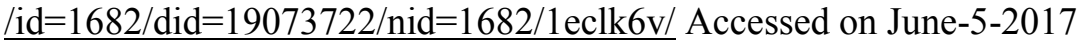

Tang C.S., 2006. Perspectives in supply chain risk management. International Journal of Production Economics, 103, 451-488.

Torabi S.A., Baghersad M., Mansouri S.A. (2015). Resilient supplier selection and order allocation under operational and disruption risks. Transportation Research Part E: Logistics and Transportation Review, 79, 22-48.

Tukamuhabwa B.R., Stevenson M., Busby J. \& Zorzini M. (2015). Supply chain resilience: definition, review and theoretical foundations for further study. International Journal of Production Research, 53(18), 5592-5623.

Wilson M.C. (2007). The impact of transportation disruptions on supply chain performance. Transportation Research Part E: Logistics and Transportation Review, 43, 295-320.

Xu M., Wang X., \& Zhao L. (2014). Predicted supply chain resilience based on structural evolution against random supply disruptions. International Journal of Systems Science: Operations \& Logistics, 1(2), 105-117.

Yu G., Li F. \& Yang Y. (2017). Robust supply chain networks design and ambiguous risk preferences. International Journal of Production Research, 55(4), 1168-1182. 